\title{
RELASI SOSIAL BUDAYA ATA KROWE DAN GUNUNG MAPITARA
}

\section{THE SOCIO-CULTURAL RELATIONS OF ATA KROWE AND MOUNT MAPITARA}

\author{
Putri Novita Taniardi \\ Balai Arkeologi D.I. Yogyakarta
}

\begin{abstract}
This paper discusses about a relation between Mount Mapitara and Ata Krowe. Mount Mapitara is a sacred mountain that has a special meaning for Ata Krowe. Ata Krowe is a name for Krowe people who lived in Krowe adat area in Kabupaten Sikka, East Nusa Tenggara on Flores Island. The question raised in this paper is: what is the meaning of Mount Mapitara for Ata Krowe and how does that meaning was symbolized by material culture among Ata Krowe. To answer these questions, the research has been conducted to explore the way material culture were being used as symbols that related to the existence of Mount Mapitara. This study is applying this study was applying theory of symbols which refer to Michael Shanks and Christopher Tilley's theory of ideology, symbolic power, and ritual communication. This theory was applied to identifiy the use of material cultures as symbol in a certain place and to define the symbol that related to Mount Mapitara. The research result indicate that there is material culture named wu'a mahe that has special meaning for Ata Krowe. Wu'a mahe is a stone altar that believed as a place where the ancestor had lived, before they were getting purified and move into Mount Mapitara as a perpetual place to stay. This paper is focusing on the relation between Mount Mapitara and Ata Krowe that can be seen from the use of material culture as symbols.
\end{abstract}

Keyword : Mount Mapitara, Ata Krowe, material culture, symbol.

\section{ABSTRAK}

Tulisan ini mendiskusikan tentang relasi antara gunung Mapitara dan Ata Krowe. Gunung Mapitara adalah gunung yang disakralkan dan memiliki makna penting bagi Ata Krowe. Ata Krowe adalah sebutan bagi orang-orang yang tinggal di wilayah adat Krowe di Kabupaten Sikka, Nusa Tenggara Timur di Pulau Flores. Pertanyaan yang dimunculkan dalam tulisan ini adalah apa makna Gunung Mapitara bagi Ata Krowe dan bagaimana pemaknaan tersebut disimbolkan dengan budaya materi yang ada pada Ata Krowe. Untuk menjawab pertanyaanpertanyaan tersebut, penelitian telah dilakukan untuk menggali informasi penggunaan budaya materi sebagai simbol yang berelasi dengan keberadaan Gunung Mapitara. Studi ini menerapkan teori simbol, merujuk teori yang digunakan oleh Michael Shanks dan Christopher Tilley: idelogi, kuasa simbolis, dan komunikasi ritual. Teori ini diterapkan untuk mengindentifikasi penggunaan budaya materi sebagai simbol yang ada pada tempat tertentu dan mendefinisikan simbol yang berelasi dengan Gunung Mapitara. Hasil dari penelitian yang telah dilakukan menunjukkan bahwa terdapat budaya materi bernama wu'a mahe yang memiliki makna khusus bagi Ata Krowe. Wu'a mahe adalah altar batu yang dipercaya sebagai tempat tinggal arwah leluhur sebelum disucikan dan nantinya pindah ke Gunung Mapitara sebagai tempat tinggal abadinya. Secara khusus, tulisan ini menekankan pada relasi antara Gunung Mapitara dan Ata Krowe dengan memperhatikan penggunaan budaya materi sebagai simbol.

Kata Kunci : Gunung Mapitara, Ata Krowe, budaya materi, simbol.

Tanggal masuk : 7 Februari 2017

Tanggal diterima : 16 Februari 2017 


\section{PENDAHULUAN}

Pemujaan terhadap gunung merupakan konsep universal yang digunakan di beberapa tempat di dunia ini. Di dalam tulisannya, Wales (1952) berpendapat bahwa pemujaan terhadap gunung perlu dicermati dan dikaji, terutama di wilayah Asia. Menurut Wales, terdapat kemiripan di kalangan bangsa-bangsa di Asia dalam memperlakukan gunung. Bahkan, kesadaran akan kesakralan gunung ini telah menciptakan "agama tua Asia" yang kemungkinan merupakan asal-usul dari agama-agama yang muncul kemudian di wilayah Asia Tenggara. Wales mencontohkan bagaimana gunung ini dikultuskan oleh orang-orang Mesopotamia dengan representasi ziggurat sebagai simbol budaya materi. Wales juga menunjukkan contoh serupa melalui tradisi di Cina dan India. Ketiga wilayah budaya ini memiliki pandangan yang sama terhadap gunung, yaitu sebagai tempat yang sakral. Simbolisasi kesakralan gunung tersebut juga sama-sama ditunjukkan melalui simbol-simbol "pengganti", seperti ziggurat di Mesopotamia, gundukan tanah kubur di Cina sebagai penghormatan kepada dewa Bumi, dan simbolisasi Gunung Meru di India.

Di Indonesia, pengultusan terhadap gunung juga dilakukan oleh masyarakat tradisional hingga sekarang. Kondisi geografis Indonesia yang kaya akan gunung berapi, baik yang aktif maupun tidak, menjadikan gunung dekat dengan budaya Indonesia. Seperti misalnya komunitas adat Krowe yang ada di Kabupaten Sikka, Flores Tengah. Orang-orang Krowe percaya bahwa gunung memiliki kekuatan sakral karena gunung merupakan tempat tinggal leluhur mereka. Menurut penuturan Mo'an Yansen, di dalam legenda yang diceritakan turun temurun, nenek moyang Orangorang Krowe yang datang dari luar Pulau Flores pernah tinggal di sekitar Gunung Mapitara. Gunung Mapitara ini tidak jauh dari Gunung Egon, gunung berapi yang masih aktif hingga saat ini. Awalnya, nenek moyang mereka datang ke Pulau Flores dengan menggunakan perahu dan mendarat di Pantai Waiterang. Di pantai ini mereka kesulitan untuk mendapatkan makanan dan air tawar. Mereka akhirnya berjalan ke arah gunung karena di tempat tersebut terdapat hewan-hewan buruan dan tumbuh-tumbuhan untuk dimakan. Sesampainya di Gunung Mapitara, mereka tinggal di tempat ini dan hidup dari hasil alam. Seiring berjalannya waktu, nenek moyang orang-orang Krowe ini menyebar ke wilayah lain di wilayah pengunungan Sikka tengah. Di tempat tinggal yang baru, mereka masih berelasi dengan Gunung Mapitara. Sebagai penghubung antara orang-orang Krowe dengan Gunung Mapitara, didirikanlah wu'a mahe yang menghadap ke arah gunung tersebut. Wu'a mahe adalah altar batu yang terdiri atas batu tegak dan batu mendatar sebagai media untuk menghormati roh leluhur. Wu'a mahe ini didirikan sebagai simbol suatu klan yang mendiami sebuah perkampungan. Setiap klan memiliki satu wu'a mahe, sehingga jumlah wu'a mahe selalu sama dengan jumlah klan yang mendiami suatu perkampungan.

$$
\text { Pengultusan terhadap }
$$
gunung yang dilakukan oleh Ata Krowe tersebut menarik untuk dikaji. Gunung dan simbolisasinya merupakan bagian dari kebudayaan Krowe yang penting untuk diungkapkan karena komunitas adat 
Krowe merupakan representasi masyarakat tradisional Indonesia yang masih menjaga tradisi mereka hingga saat ini. Oleh karena itu, tulisan ini berusaha menjawab permasalahan berupa:

1. Apa makna Gunung Mapitara bagi Ata Krowe?

2. Apakah makna penting Gunung Mapitara ini direpresentasikan oleh budaya materi tertentu sebagai simbol?

3. Apakah simbolisasi tersebut juga sekaligus merepresentasikan identitas Ata Krowe?

Simbol hanya dapat dimaknai ketika ia berelasi dengan simbol lainnya. Begitu pula dengan budaya materi sebagai simbol dan relasinya dengan gunung Mapitara pada komunitas adat Krowe. Relasi antar simbol tersebut dapat mengungkap kognisi masyarakat Krowe ketika dibaca pada konteks relasional.

Tujuan penulisan artikel ini adalah mendeskripsikan makna gunung bagi komunitas adat Krowe. Pengultusan terhadap gunung tidak hanya berhenti pada gunung secara fisik, tetapi juga muncul pada budaya materi yang dijadikan simbol. Relasi antara gunung dan simbol-simbol tersebut dapat menggambarkan tradisi orang Krowe secara utuh sebagai bagian dari kognisi akan identitas mereka. Tulisan ini juga bertujuan untuk memberikan pemaparan tentang bagaimana implikasi akan simbolisasi Gunung Mapitara dengan budaya materi yang berelasi dengan kehidupan orang-orang Krowe.

\section{Tinjauan Pustaka}

Permukiman tradisional yang mengacu gunung sebagai salah satu simbol budayanya terdapat di Ngada, Flores. Sudarmadi (1999) di dalam tesisnya mengulas bagaimana permukiman berciri budaya megalitik dan simbol-simbol di dalamnya saling berelasi. Desa Nage dipilih Sudarmadi (1999) sebagai lokasi penelitian utama untuk penelitian tesisnya.

Nage adalah bagian dari kumpulan desa, dibangun di atas punggung gunung Inerie, 700 meter di atas dan $1 \mathrm{~km}$ dari sungai Waebana, kumpulan dan dikelilingi oleh hutan bambu. Desa terdiri atas Desa Nage, Nio, Wajo, dan Bowaru. Kesatuan desa-desa ini tampak dalam pernyataan 'ulu nage eko waru', yang berarti bahwa kepala (bagian depan) desa terletak di Nage dan ekor di Waru. Memang struktur batu yang disebut watu ulu nua, yang menandai pintu masuk utama ke komposit desa (eko nua) ada di pintu keluar Bowaru.

Sumbu pintu masuk / keluar desa berorientasi pada puncak Gunung Inerie, dan karena itu terletak sejajar dengan lereng dalam kasus Nage, ini adalah timurbarat. Pintu masuk terletak di ujung bawah desa. Sisi kiri dan kanan desa menghadap ke lereng. Sisi kiri desa menghadap ke selatan dan sisi kanan menghadap ke utara.

$$
\text { Halaman perkampungan }
$$

Nage membentang sepanjang wilayah desa dan terdiri atas tiga teras yang menaik dengan dinding batu di sekitarnya-loka Luba nee Metu, loka Dizzi nee Deru dan loka Tegu. Tiap-tiap teras dimiliki ole woe (sub-klan) yang berbeda-beda (Sudarmadi, 1999: 116-120).

Loka Teras batu terendah, dekat dengan pintu masuk desa, dimiliki oleh woe Luba dan woe Metu. Sebelumnya, kedua sub-klan tersebut memiliki simbol identitas yang didirikan di sini, namun woe 
Luba dipindahkan ke desa Bowaru saat woe Luba pindah. Di masa lalu, megalit (ture) juga dibawa agak jauh ke desa baru. Biasanya batu-batu itu dikumpulkan dari batu andesit, yang mudah ditemukan di sekitar Gunung Inerie.

Woe di desa Ngada menguasai banyak lahan, tersebar di wilayah yang luas. Semua tanah woe milik bhaga-ngandhu dan disebut tana ngandhu-bhaga. Akses terhadap tanah woe ditentukan di rumah adat (sao). Sebagian besar hak atas sumber daya ini ditentukan oleh hubungan sao tua-muda, sao wanita-pria. Biasanya, tanah woe melewati rumah tradisional wanita tua (sao saka lobo), disebut lanu saka lobo. Dengan waktu, keturunan bisa beralih dari sao saka puu / sao saka lobo dan membangun rumah mereka sendiri (sao doro). Dalam hal ini tanahnya bisa dibeli dari lanu saka puu / lanu saka lobo. Tanah yang dibawa oleh sao doro semacam itu disebut padhi sae (Sudarmadi, 1999: 177).

Legitimasi klaim lahan

Ngadha oleh woe ditentukan oleh mitologi woe. Biasanya mitos semacam itu mengacu pada asal mula woe dan cara nenek moyangnya ditemukan (Sudarmadi, 1999:178). Mitos asal-usul woe adalah yang paling penting dalam mengakses tanah woe, karena mengakses tanah milik nenek moyang yang buruk. Penatua (tetua) bersikeras bahwa mereka hanya menempati tanah yang diwarisi dari nenek moyang woe mereka. Mereka memiliki hak untuk menempati tanah, mengolahnya, dan menghasilkan hasil, yang bisa dijual sesuka mereka. Mereka mungkin tidak dihapus dari akses tanah, juga tidak memiliki hak untuk menjualnya, atau untuk menentukan keturunan mana yang harus mendapatkan bagian utama (Sudarmadi, 1999:74).

Sama seperti dengan orang Ngadha, kepemilikan lahan di kalangan Ata Krowe juga terkait dengan nenek moyang mereka. Setiap suku yang mendiami sebuah kampung memiliki akses terhadap lahan yang dimiliki secara turuntemurun. Tanah ini dinamakan tana wawi pepiara piong. Lahan ini dimiliki oleh setiap suku dan jatuh pada hak kesulungan, yaitu anak laki-laki tertua di tiap-tiap suku. Di tana wawi pepiara piong ini, setiap suku mendirikan rumah utama yang disebut lepo gete. Di belakang tanah utama, terdapat lahan kebun yang bisa ditanami dan dijual hasil panennya. Lahan ini disebut juga sebagai lahan adat yang hanya boleh diolah tetapi tidak boleh diperjualbelikan.

Setiap kampung di wilayah adat Krowe dipimpin oleh tuan tanah yang dikenal sebagai tana puan. Tana puan ini yang kemudian memiliki hak untuk menentukan pembagian lahan bagi setiap suku yang bermukim di sebuah kampung. Di Kampung Romanduru misalnya, tana puan di kampung ini berasal dari suku Buang Baling dan memimpin sembilan suku lainnya yang tinggal di sana. Nenek moyang suku Buang Baling adalah orang yang pertama kali datang dan membuka kampung Romanduru dan menentukan suku-suku yang boleh menetap di kampung tersebut. Nenek moyang ini kemudian menjadi tana puan dan menurunkan kepemimpinannya ini kepada anak cucunya. Nenek moyang suku Buang Baling dulunya juga membagi tanah-tanah ada bagi setiap suku yang datang dan menetap di Kampung Romanduru dan dimiliki hingga saat ini. 
Perkampungan di wilayah adat Krowe memiliki kemiripan dengan desa di Ngadha yang mengacu Gunung Inerie. Kampung Romanduru mengacu Gunung Mapitara sebagai simbol kosmologis. Gunung Mapitara dipercaya sebagai tempat asal-usul nenek moyang mereka dan tempat tujuan akhir mereka ketika meninggal nanti. Di tengah-tengah perkampungan, didirikan mahe yang dimiliki oleh tiap-tiap suku yang tinggal di kampung tersebut dengan arah hadap ke Gunung Mapitara.

Tulisan yang banyak mengulas tentang Komunitas Adat Krowe selama ini dilakukan secara konsisten oleh Butterworth (2008; 2009; 2011). Secara berturut-turut, Butterworth menuliskan tentang ritual adat yang ada di kalangan orang Krowe, kedudukan Tana $P u$ 'an dalam organisasi sosial Orang Krowe, dan inovasi yang terjadi dalam pelaksanaan ritual Lodong Me. Karya etnografi terbaru yang mengulas tentang komunitas adat Krowe adalah tulisan Utama (2014) yang melakukan penelitian dengan topik transformasi ritual adat di kalangan Ata Krowe. Karya-karya etnografi tersebut berfokus pada aspek ritual dan organisasi sosial yang ada di kalangan orang Krowe. Minimnya tulisan tentang orang Krowe ini menunjukkan masih banyak peluang yang dapat dilakukan untuk mengungkap kebudayaan orang Krowe, salah satunya yang memfokuskan tentang pengaturan lahan dengan simbolsimbol material.

Satu tulisan yang secara spesifik mengulas keberadaan watu mahe ditulis oleh Theresia Sero (2015) sebagai karya tulis ilmiah berupa skripsi. Sero menguraikan dengan detail keberadaan watu mahe di Dusun Romanduru, Desa
Rubit, Kecamatan Hewokloang, Kabupaten Sikka. Sero memfokuskan tulisannya pada aspek sosial watu mahe, yaitu sebagai lambang dari kehadiran suku-suku yang ada di Romanduru. Sero juga menguraikan bagaimana relasi sosial di dalam masyarakat Romanduru beserta ritual-ritual yang masih dilaksanakan hingga sekarang. Dalam membungkus uraiannya, Sero menggunakan analisis fungsional, dengan menekankan fungsi watu mahe itu sendiri. Sero menyebutkan bahwa watu mahe memiliki fungsi religi, fungsi sosial, dan fungsi persatuan. Karya tulis lain yang berupa skripsi dengan tema peninggalanpeninggalan megalitik ditulis oleh Fransiska Purnamawati Matutina. Matutina (1995) menuliskan tentang peninggalan-peninggalan megalitik di Kampung Dobo, Desa Ian Tena, Kecamatan Kewapante, Kabupaten Sikka. Matutina menyebutkan bahwa di Kampung Dobo terdapat tinggalan-tinggalan megalitik berupa menhir atau mahe, berupa: watu isung Tana Puan, watu mangun lajar, watu hoban puan, watu tana wura, dan watu tadak. Tinggalan megalitik lainnya berupa dolmen atau nabe yang dinamakan watu goban, tahta batu dengan nama watu sado pun, dan perahu perunggu atau dikenal dengan jong dobo. Sama halnya dengan Sero, Matutina membungkus analisisya dengan menekankan pada aspek fungsional. Dalam analisisnya, Matutina menyebutkan bahwa fungsi dan bentuk-bentuk peninggalan megalitik adalah sebagai: sarana pemujaan kepada arwah leluhur yang diberi gelar Nitu Mateng atau Nitu Noang; tanda peringatan bagi arwah leluhur; tempat untuk mengikat tali binatang yang akan dikorbankan pada upacara-upacara 
adat; dan sebagai pelengkap dalam upacara-upacara yang berkaitan dengan kesuburan dan kemakmuran.

Satu tulisan etnografis yang menyinggung tentang kepemilikan lahan secara komunal telah ditulis oleh Philipus Tule (2006) dengan judul "We are children of the Land: $A$ Keo Perspective". Tule mencermati masalah lahan di kalangan masyarakat Keo, di mana menurut orang-orang Keo, tanah tidak dimiliki oleh individu-individu, melainkan tanahlah yang memiliki mereka. Lahan bagi masyarakat Keo adalah lahan adat, yang dimiliki oleh leluhur. Pengaturan lahan ini kemudian diatur oleh tuan tanah yang mengklaim sebagai keturunan dari leluhur orang-orang Keo. Orangorang Keo dapat mengolah tanah secara individual, tetapi tidak dapat memilikinya. Pengolahan lahan menjadi lahan pertanian misalnya, dapat dilakukan oleh anggota keluarga dalam satu garis keturunan leluhur yang memiliki tanah, tetapi tidak boleh menghalangi anggota keluarga lain yang hendak mengolah tanah juga. Selain itu, pengolah tanah harus menghormati leluhur yang telah memberikan tanah dengan memberikan sumbangan makanan dan binatang-binatang bila ada upacara ritual yang diselenggarakan di desa (Tule, 2006: 11-220).

Tulisan-tulisan yang mengulas tentang budaya materi (watu mahe dan tinggalan-tinggalan megalitik lainnya) dan relasinya dengan pengultusan gunung maupun aspek kosmologis lainnya belum diulas oleh peneliti-peneliti tersebut. Oleh karena itu, penelitian tentang budaya materi dan relasinya dengan gunung penting untuk dilakukan. Penelitian ini berbeda dengan penelitianpenelitian sebelumnya, karena berusaha untuk mencermati hubungan relasional antara budaya materi sebagai simbol bagi Ata Krowe dan pengultusan gunung oleh orang-orang Krowe.

\section{Landasan Teori}

Beberapa ahli ilmu sosial mendefinisikan simbol dari berbagai perspektif. Salah satunya adalah Spiro yang menyebutkan bahwa simbol adalah "a sign which refers to the object that it denotes by virtue of a law, usually an association of general ideas, which operates to cause the symbol to be interpretde as referring that object (Maquet, 1980:4). Ahli ilmu sosial lain yang mendefinisikan tentang simbol adalah Fernandez, yang menyebutkan bahwa : they (symbol) mediate between what is perceived by the sense and what is built in the mind.... one symbol stands for more than one object (or class of object) (Maquet, 1980: 6). Sementara menurut Tilley (2006), the meaning of symbol is not arbitrary, it is relational. Selanjutnya, AhimsaPutra (2014) menyebutkan bahwa simbol adalah "segala sesuatu yang dimaknai". Simbol, menurut AhimsaPutra, mempunyai dua dimensi, yaitu pelambang (yang melambangkan) dan linambang (yang dilambangkan). Pelambang dan linambang ini bersifat arbitrer yang didasari kesepakatan. Pernyataan lain diuraikan oleh Spradley yang menjelaskan bahwa makna suatu simbol merupakan hubungan simbol tersebut dengan simbol-simbol yang lain. Artinya, untuk memahami simbol-simbol budaya tidaklah cukup dengan menemukan rujukan atas sebuah simbol, melainkan juga menemukan dan mendeskripsikan hubungan yang terjadi di antara simbol tersebut 
dengan simbol-simbol yang lain (Spradley, 1979: 97).

Gunung Mapitara bagi Ata

Krowe bukan semata-mata objek materi yang berupa lanskap dataran tinggi, berjurang dengan ngaraingarainya, sebaliknya gunung tersebut merupakan peta yang menurut Shank dan Tilley (1982: 129-154) merepresentasikan ideologi, kekuasaan simbolis, dan komunikasi ritual. Menurut kedua ahli ini , sistem simbol hadir sebagai perangkat struktur. Sebagai peta ideologi, hal ini tampak pada cerita asal-usul nenek moyang mereka sebagai berikut.

Gunung Mapitara memiliki arti yang penting bagi Orang Krowe. Mapitara merupakan tempat pemukiman warga sejak awal kehidupan manusia di Flores. Waktu itu, ada dua orang bersaudara dari $\operatorname{Irian}^{1}$ melakukan penjelajahan. Dua orang tersebut bernama Du'a Koi Waimeni dan Mo'an Dolesoba. Dalam penjelajahannya, mereka terdampar di Waiterang, pantai di dekat Maumere. Karena pinggir pantai tidak mencukupi kebutuhan hidup, mereka kemudian melakukan perjalanan ke arah Gunung Egon. Gunung Egon yang masih aktif tidak layak untuk dijadikan tempat tinggal, sehingga mereka melanjutkan perjalanan kembali ke arah selatan. Perjalanan mereka terhenti setelah menemukan Gunung Mapitara dan menetap di sana. Di tempat ini mereka tinggal dan mencukupi kebutuhan makanan dengan mengumpulkan umbi-umbian yang ada di sekitar gunung dan berburu binatang liar. Pada saat kedua bersaudara itu datang ke Mapitara, belum ada orang yang hidup di daratan Flores. Mereka hanya hidup berdua di Gunung Mapitara tersebut.

${ }^{1}$ Nama lain untuk Papua
Hingga pada suatu hari, kedua bersaudara ini cekcok lalu memutuskan untuk pergi masingmasing menuju arah yang berlawanan. Selama beberapa waktu kemudian, mereka bertemu kembali dalam rupa yang sangat lain sehingga tidak saling mengenali. Kedua orang itu kemudian menikah dan melahirkan keturunan, tiga lakilaki dan dua perempuan.

Dalam perjalanan hidup mereka, ketiga anak laki-laki dan kedua anak perempuan mulai menjelajah masing-masing untuk mencari tempat tinggal. Anak-anak laki-laki, yaitu Kei, Laet, dan Dupa menduduki wilayah Pogon, Rubit, dan Wolomotong. Kemudian Laet menjelajah lagi ke wilayah timur, ke Tana Ai, dan tinggal di Talibura. Saudara perempuannya yang dua orang, yaitu Liwan dan Lodar menjelajah ke selatan sampai ke Halehebin. Karena waktu itu ada bencana, Lodan kembali lagi ke daerah Mapitara. Sedangkan Liwan pergi ke arah barat sampai terdampar di Lela Sikka. Lodar kemudian menikah dengan pendatang yang bernama Desidemo. Mo'an Laet yang menetap di Tana Ai kemudian menikah dengan orang Helang ${ }^{2}$. Mo'an Kei tinggal di Koker dan menikah dengan pendatang dari Selayar. Dupa menikah dengan pendatang dari Keitimu. Dari seluruh keturunan Du'a Koi Waimeni dan Mo'an Dolesoba, Kei, Laet, dan Dupa merupakan nenek moyang Ata Krowe saat ini.

Bagi Ata Krowe, peta kekuasaan sangat bergantung pada relasi dengan nenek moyang yang pertama kali menghuni sebuah kampung. Seperti misalnya di

\footnotetext{
${ }^{2}$ Di kalangan orang Jawa dikenal sebagai kuntilanak
} 
Kampung Romanduru. Di kampung ini, Tuan Tanah atau dikenal sebagai Tana Pu'an berasal dari suku Buang Baling. Suku ini merupakan suku yang pertama kali datang dan membuka kampung Romanduru. Suku Buang Baling juga yang menentukan suku-suku lain boleh tinggal dan menetap di kampung ini. Hingga saat ini, terdapat sepuluh suku yang menetap di Kampung Romanduru, di bawah kepemimpinan suku Buang Baling.

Sebagai hubungan sosial melibatkan simbolisme, bentuk ideologi dan bentuk simbolis akan terikat erat bersama-sama. Untuk menganalisis aspek ideologis dari perintah simbolis adalah dengan menyelidiki cara di mana struktur penandaan yang digunakan untuk melegitimasi posisi kelompokkelompok tertentu. Simbol dapat secara aktif digunakan untuk memobilisasi dan kepentingan seksional yang sah (Shank dan Tilley,1982: 132). Bentuk persepsi budaya material dapat bertindak baik di tingkat diskursif, atau lebih kuat, karena kemungkinan besar tidak akan diakui, pada tingkat kesadaran praktis untuk struktur praktek sosial. budaya material merupakan bagian dari bentuk fenomenal ideologi. Apa yang hadir untuk arti dalam simbolisme dalam budaya materi harus aktif diproduksi oleh agen. (Shank dan Tilley,1982: 133).

Kesadaran praktis ini kemudian dibagikan kepada komunitas yang bermukim di tempat yang sama secara turun-temurun. Kesadaran ini kemudian disepakati menjadi kesadaran kolektif yang kemudian menjadi pengalaman yang dilaksanakan secara berkelanjutan. Kesadaran yang kemudian menjadi pengalaman ini merupakan langkahlangkah penerapan fenomenologi.
Fenomenologi memandang perilaku dan tindakan manusia sebagai sesuatu yang bermakna, karena manusia memberikan makna pada perilaku dan tindakan tersebut. Makna ini lahir dari kesadaran manusia akan perilaku dan tindakannya serta tujuan-tujuan yang dikenakannya pada perilaku dan tindakan tersebut. Makna-makna yang diberikan ini ada yang bersifat individual, ada pula yang sosial, kolektif, artinya makna tersebut bersifat intersubjektif, dimiliki oleh orang lain juga. Makna yang kolektif ini bisa terbentuk karena manusia berinteraksi, berkomunikasi satu dengan yang lain dengan menggunakan bahasa lisan. Adanya makna kolektif yang merupakan kesadaran kolektif (collective consciousness) inilah yang melahirkan perilaku-perilaku kolektif (Ahimsa, 2012: 284).

\section{METODE}

Penelitian ini dilakukan di Desa Rubit dan Desa Baomekot, Kecamatan Hewokloang, Kabupaten Sikka, Nusa Tenggara Timur. Lokasi ini dipilih karena Desa Rubit masih menggunakan budaya materi sebagai simbol. Simbol tersebut berupa wu'a mahe sebagai identitas tiap-tiap klan. Teknik pengumpulan data yang digunakan adalah studi pustaka, observasi, survei budaya materi, dan wawancara. Studi pustaka meliputi tulisan-tulisan hasil penelitian sebelumnya, baik penelitian yang berlokasi di Kabupaten Sikka maupun penelitian di lokasi lain di wilayah Pulau Flores. Penelusuran pustaka juga meliputi hasil penelitian di tempat lain dengan tema megalitik, pemanfaatan lanskap, ataupun tema serupa. Hal ini dilakukan sebagai perbandingan dengan kondisi yang 
ada di Desa Rubit. Dengan mengetahui hasil-hasil penelitian yang terfokus pada permukiman megalitik mapun lanskap, diharapkan dapat memunculkan sebuah data baru yang dapat melengkapi data yang telah ada sebelumnya.

Teknik pengumpulan data yang kedua adalah observasi. Observasi dilakukan untuk mencari data terkait pola permukiman, pengaturan lahan, dan aspek-aspek penting dalam permukiman di Desa Rubit. Observasi ini penting dilakukan pada awal-awal penelitian sebagai bentuk penyesuaian diri di lapangan dan mendapatkan akses informasi lebih lanjut. Observasi ini dibagi menjadi dua, yaitu observasi aktivitas manusia dan observasi budaya materialnya. Dengan melakukan kedua observasi ini diharapkan mampu memunculkan strategi survei yang dilakukan selanjutnya. Survei tinggalan budaya materi difokuskan pada bendabenda monumental seperti Wu'a Mahe, Ai Tali, dan Watu Mahang. Survei ini meliputi perekaman data secara grafis, berupa gambar dan foto dan data numerik berupa pengukuran.

Memahami pemaknaan Ata

Krowe akan lanskap budayanya melalui simbol-simbol budaya materi dapat dilakukan dengan pendekatan fenomenologi. Pembacaan akan lanskap dengan pendekatan fenomenologi telah dilakukan oleh Christopher Tilley (1994). Di dalam bukunya, Tilley menyebutkan bahwa pendekatan ini terinspirasi dari ilmu geografi di mana memaknai ruang tidak hanya sebatas lokasi, tetapi juga merujuk pada aktivitas yang dilakukan di dalamnya. Isu utama dalam pendekatan fenomenologi adalah cara manusia memahami dan memiliki pengalaman akan dunia. Fenomenologi melibatkan pandangan dan gambaran akan benda-benda yang dialami oleh subjek. Tilley (1994: 12) menyebutnya "it is about the relationship between Being and Being-in-the-world." Being-in-theworld merupakan proses dari sebuah objektifikasi di mana orang menunjuk sebuah dunia yang merupakan bagian dari dunia tersebut. Penyebutan akan dunia yang orang tunjuk melibatkan penciptaan jarak antara orang dan dunia tersebut. Untuk menjembatani jarak tersebut, diperlukan beragam pemaknaan, yaitu melalui persepsi (melihat, mendengar, dan menyentuh), gerakan-gerakan dan aktivitas tubuh, dan intensitas yang terlihat pada emosi dan kesadaran akan sistem kepercayaan dan pembuatan keputusan, ingatan, dan evaluasi.

Berdasarkan uraian Tilley mengenai definisi fenomenologi tersebut, dapat diketahui bahwa pendekatan fenomenologi merupakan pendekatan yang mensyaratkan adanya pengalaman individu. Oleh karena itu, Tilley mengungkapkan bahwa pemaknaan akan benda-benda dapat diperoleh melalui persepsi, yang didalamnya terdapat proses melihat, mendengar, dan merasakan secara langsung. Melalui pengalaman secara langsung ini, individu dapat berempati dengan apa yang menjadi subjeknya. Bila diaplikasikan dalam pembacaan sebuah lanskap, tentu persepsi ini perlu untuk diformulasikan kembali supaya tidak terjadi bias. Seperti misalnya pemahaman akan "individu" yang dimaksud, apakah peneliti atau pelaku kebudayaan. Subjektivitas ini kemudian perlu dicermati dengan seksama, terutama bagaimana pengalaman individu kemudian 


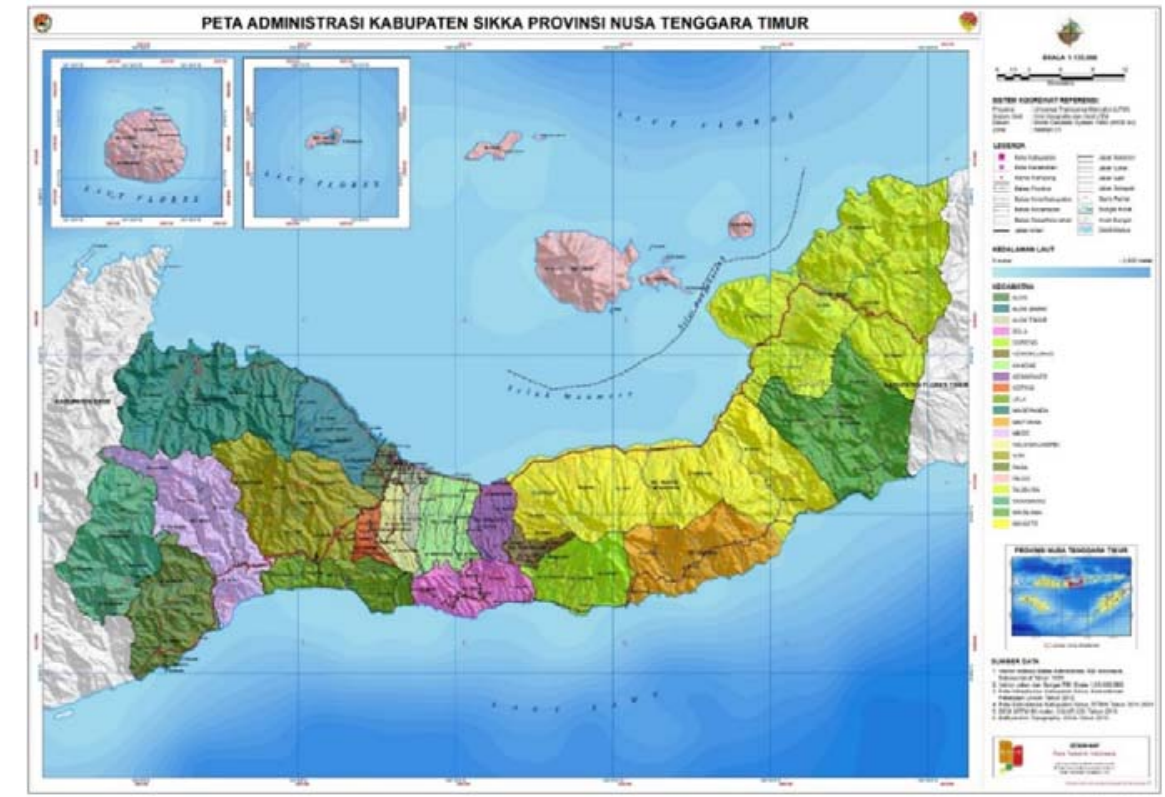

Gambar 1. Peta Kabupaten Sikka (Sumber: Dokumentasi Tim Penelitian)

disepakati menjadi gagasan komunal.

Pada konteks budaya Ata Krowe, pengalaman tersebut telah terinternalisasi menjadi pengalaman kolektif. Semua suku pada Komunitas Adat Krowe sama-sama memiliki pola yang sama. Semua menjalankan tradisi ngen, yaitu pindah dari satu tempat ke tempat lain untuk menjaga kelangsungan hidup mereka. Di manapun mereka tinggal, mereka segera mendirikan Wu'a Mahe yang berelasi dengan Gunung Mapitara dan bermakna sakral. Wu'a Mahe sekaligus menjadi identitas setiap suku di suatu perkampungan. Jumlah wu'a mahe selalu sama dengan jumlah suku yang mendiami suatu natar atau kampung.

\section{HASIL PENELITIAN}

\section{Gambaran Fisiografi Umum Kabupaten Sikka}

Kabupaten Sikka merupakan bagian dari Provinsi Nusa Tenggara
Timur (NTT) yang terletak di Pulau Flores. Secara astronomis, kabupaten Sikka terletak di antara $8^{0} 22^{\prime}-8^{0} 50^{\prime}$ LS dan $121^{\circ} 55^{\prime}-122^{\circ} 41^{\prime}$ BT. Daratan Sikka berupa daerah landai dan perbukitan dengan luas $1.713,91 \mathrm{~km}^{2}$. Batas kabupaten Sikka sebelah utara adalah Laut Flores, batas sebelah selatan adalah Laut Sawu, batas sebelah Barat adalah Kabupaten Ende, dan batas sebelah timur adalah kabupaten Flores Timur.

Sebagai bagian dari Pulau Flores, Kabupaten Sikka memiliki karakteristik geoanticline yang serupa dengan Pulau Flores. Flores terdiri dari anticline berorientasi timur-barat yang membentang pada pulau dengan jarak lebih dari 350 $\mathrm{km}$. Fitur yang menonjol dari pulau Flores adalah jajaran gunung berapi aktif dan bentuk-bentuk yang lebih tua dari vulkanisme. Contoh yang baik adalah kaldera dari danau kelimutu di Flores tengah dengan tiga danau warna. (Metzner,1982: 20). 


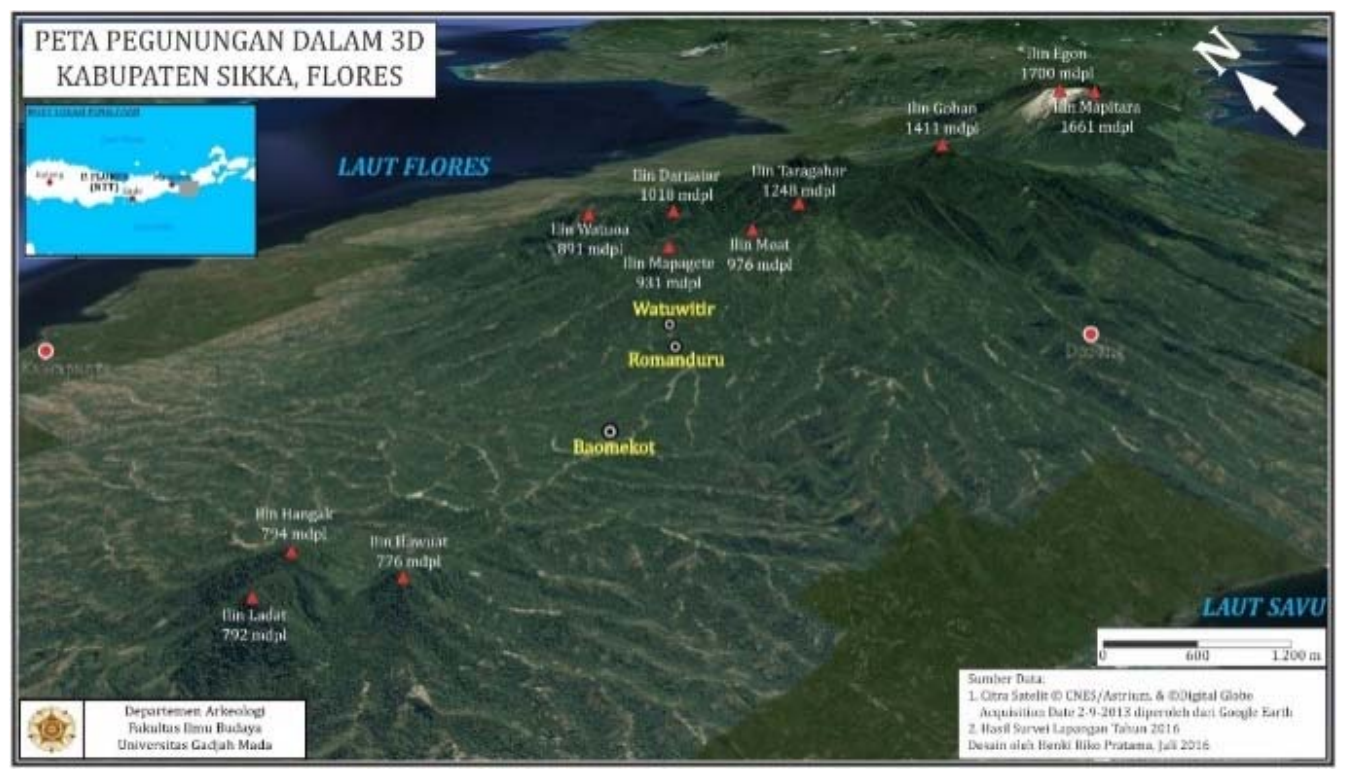

Gambar 2. Peta Pegunungan Kabupaten Sikka (Oleh: Henki Riko Pratama, 2016)

Kondisi geomorfologi Sikka tersebut menunjukkan bahwa di wilayah ini terdapat banyak pegunungan. Gunung diyakini memiliki makna sakral dan penting bagi kehidupan Ata Krowe. Pembahasan mengenai Gunung yang memiliki makna penting bagi Ata Krowe, diuraikan pada bagian berikutnya.

\section{Ata Krowe: Orang Gunung di Tana Sikka}

Komunitas adat Krowe
merupakan sebutan bagi masyarakat penutur bahasa Sikka yang menghuni kawasan Ili/ Kangae (Butterworth, 2008). Kawasan Ili/ Kangae ini merupakan bagian dari Kabupaten Sikka, Flores Tengah. Komunitas adat Krowe dikenal juga sebagai Ata Krowe, merujuk pada kata Krowe yang berarti gunung dan Ata yang berarti orang. Dengan demikian, sebutan Ata Krowe ini menunjukkan identitas mereka sebagai orang gunung, wilayah tempat tinggal mereka. Ata Krowe tinggal di wilayah pegunungan di kabupaten Sikka bagian tengah.
Bahasa yang mereka gunakan adalah bahasa Krowe, salah satu ragam bahasa di antara penutur bahasa-bahasa di Sikka.

Gambaran tentang Ata Krowe dalam kaitannya dengan Sikka diulas oleh Butterworth (2015) di dalam kumpulan tulisan dengan judul "Pemburu yang Cekatan" ( Lee dan Prior, 2015). Di bagian awal artikel ini Butterworth menjelaskan perbedaan di antara tiga komunitas pengguna Bahasa Sikka (Sara Sikka). Komunitas pertama berada di bagian paling timur Sikka disebut Ata Tana Ai (Orang Tana Ai). Di bagian paling Barat terdapat komunitas Ata Sikka (Orang Sikka). Terakhir, di antara kedua komunitas tersebut terdapat Ata Krowe (Orang Krowe).

Pada penelitian ini, yang dimaksud dengan Ata Krowe adalah orang-orang Krowe yang tinggal di wilayah Desa Rubit dan Baomekot. Desa Rubit dan Desa Baomekot berada di wilayah Kecamatan Kewokloang, Kabupaten Sikka, Flores Tengah. Wilayah penelitian difokuskan pada kampung 
Romanduru, yang berada di wilayah administrasi Desa Rubit. Kampung Watuwitir yang juga masih merupakan bagian dari wilayah Desa Rubit disebutkan dalam tulisan ini sebagai acuan perbandingan. Kampung Baomekot yang berada di wilayah administrasi Desa Baomekot juga merupakan tempat tinggal orang-orang Krowe yang diacu sebagai pengaya referensi.

\section{Lanskap Budaya Kampung Romanduru sebagai Tempat Tinggal Ata Krowe \\ Menurut Santosa dan} Muta'ali (2014:82), lanskap budaya atau bentang budaya adalah hasil bentukan budaya manusia untuk memenuhi kebutuhan hidupnya. Bentang budaya terdiri atas budaya fisik dan nonfisik. Bentang budaya fisik meliputi sawah, ladang, permukiman, dan sebagainya. Bentang budaya nonfisik meliputi tradisi, kebudayaan, tari-tarian, norma, dan perilaku masyarakat lainnya yang sangat menentukan bentuk bentang budaya fisik yang tampak. Kampung Romanduru memiliki lanskap budaya yang khas. Dari cerita asal usul Romanduru, tujuan awal orang menetap di kampung Romanduru ini karena di tempat ini terdapat mata air. Mata air merupakan kebutuhan vital untuk minum, mandi, mencuci, dan sebagainya. Setelah mendapatkan mata air, berdasarkan cerita pada asal-usul kampung Romanduru, mereka mulai membangun tempat tinggal dan menggarap ladang, kemudian mendirikan Wu'a Mahe. Wu'a Mahe terdiri atas batu tegak dan mendatar. Walaupun pada gambar terlihat batu yang tegak ada yang terdiri atas lebih dari satu batu, tetapi syarat utama pendirian Wu'a Mahe adalah satu batu tegak dan satu batu mendatar. Batu tegak dan batu mendatar ini merupakan simbol atas leluhur yang mereka yakini. Batu mendatar berupa lempeng batu menyimbolkan Ina Nian Tana Wawa atau dikenal denggan Ibu Bumi. Batu tegak berupa batu menyerupai menhir menyimbolkan Ama Lero Wulan Reta atau dikenal dengan Bapak Langit. Batu tegak dan batu mendatar tersebut menyimbolkan keberadaan Bapak Langit dan Ibu Bumi, konsep religi yang mereka yakini hingga saat ini. Ibu Bumi mereka hormati karena manusia berasal dari tanah. Bumi juga menyediakan kebutuhan hidup mereka berupa air, tumbuhtumbuhan, dan tempat hidup binatang-binatang. Bapak Langit mereka hormati karena mereka percaya bahwa langit merupakan tempat tinggal leluhur-leluhur yang sudah meninggal. Mereka yang masih hidup pun nantinya akan menuju ke langit bersama leluhurleluhurnya. Wu'a Mahe yang ada di Romanduru berjumlah 10 buah, sesuai dengan jumlah suku yang mendiami kampung Romanduru. 

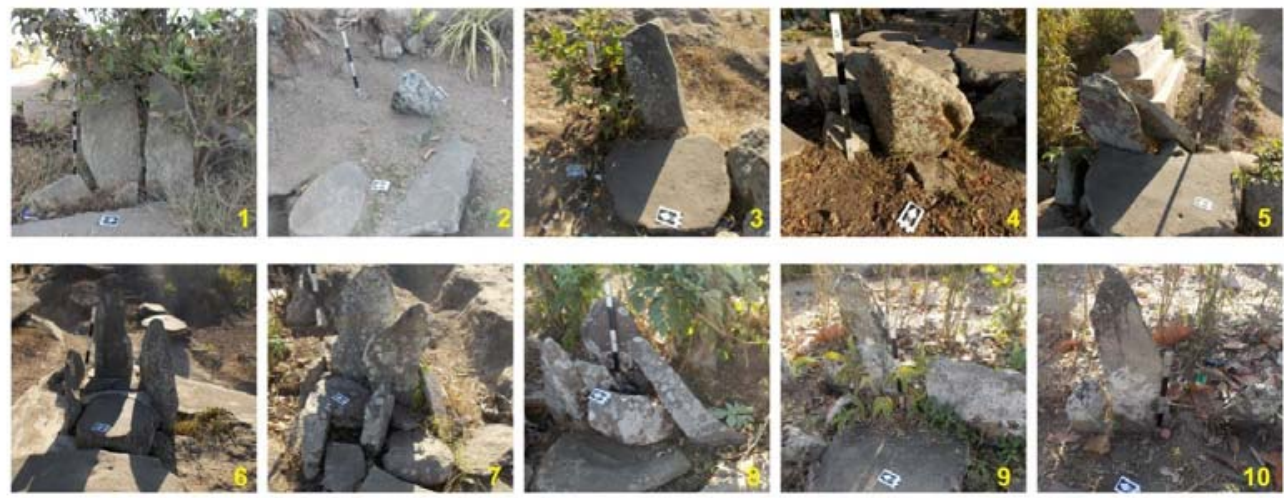

Gambar 3.Wu'a Mahe-Wu'a Mahe di Kampung Romanduru

(Sumber: penulis)

Keterangan:

1. Wu'a Mahe Ili Lewa, 2. Wu'a Mahe Wodon, 3. Wu'a Mahe Wewe Niur, 4. Wu'a Mahe Lio Lepo Gai, 5. Wu'a Mahe Buang Baling, 6. Wu'a Mahe Lio Watu Bao, 7. Wu'a Mahe Keitimu Lamen, 8. Wu'a Mahe Klukut Mude Lau, 9. Wu'a Mahe Keitimu Wain, 10. Wu'a Mahe Mana

Wu'a mahe-wu'a mahe ini
terletak di tengah-tengah
perkampungan, menyatu dengan
warga Romanduru. Tiap-tiap suku
merawat wu'a mahenya masing-
masing dan saling menghormati
wu'a mahe-wu'a mahe milik suku
lainnya. Terdapat kepercayaan
bahwa wu'a mahe-wu'a mahe
tersebut harus dibiarkan saja apa
adanya, tanpa perlu diberi
perawatan yang berlebihan, seperti
misalnya diperkuat dengan semen. Batu tegak yang roboh pun bila hendak diperbaiki posisinya harus menunggu pesan dari leluhur melalui mimpi dan melakukan ritual terlebih dahulu. Tradisi untuk menghormati Wu'a Mahe ini diturunkan kepada anak cucu masing-masing. Tidak hanya menghormati wu'a mahe milik keluarga sendiri, tetapi juga wu'a mahe milik suku lain.

Lokasi pendirian wu'a mahe biasanya tidak jauh dari lokasi tempat tinggal. Orang Krowe mengenal tempat pendirian rumah ini sebagai wisung wangar. Wisung wangar ini berupa sebidang tanah, di mana di dalamnya terdapat rumah induk milik satu suku. Bila masih ada sisa lahan, boleh didirikan satu rumah lagi, tetapi tidak dijadikan rumah induk. Rumah induk atau dikenal sebagai Lepo Gete ditinggali oleh anak laki-laki tertua dari tiaptiap suku. Meskipun demikian, kondisi ini tidak kemudian berlaku ketat. Seperti misalnya Lepo Gete milik suku Buang Baling, yang kebetulan menjadi Tana Puan di kampung Romanduru. Lepo Gete milik suku Buang Baling saat ini ditinggali oleh Abdon, anak laki-laki kedua di suku Buang Baling. Anak laki-laki tertua, Firmus, memilih untuk membangun rumah di samping Lepo Gete sepulangnya dari merantau di Kalimantan.

Di dalam Lepo Gete, di sudut kanan, di dalam kamar paling depan, terdapat batu sudut yang dinamakan watu mahang. Watu mahang ini didirikan pada saat pembangunan rumah. Di atas batu sudut tersebut, bagi suku-suku yang memiliki hak atas Tana Howakhewer, diletakkan batang bambu yang di dalamnya berisi gading, emas, biji-bijian, batubatu kecil, dan kayu-kayu kecil. Batang bambu berisi benda-benda pusaka ini dinamakan mokung. 
Suku-suku yang tidak memiliki hak atas Tana Howakhewer, di atas batu sudutnya tidak terdapat mokung, melainkan hanya lempengan batu mendatar saja. Sama seperti wu'a mahe, batu sudut juga bermakna sakral. Biasanya, ritual-ritual domestik dalam lingkup keluarga inti dilakukan di tempat ini. Setiap rumah wajib memiliki batu sudut ini, tidak hanya di Lepo Gete saja. Akan tetapi, peletakan mokung hanya di watu mahang yang terdapat di Lepo Gete.

Selain wisung wangar, wu'a mahe, dan watu mahang, tempat sakral bagi Orang Krowe adalah ai tali. Seperti telah dijelaskan pada tulisan sebelumnya, ai tali terletak di Tanah Pusaka tiap-tiap suku. ai tali milik suku Buang Baling terletak di tanah pusaka yang sekarang dikelola oleh Firmus selaku anak laki-laki tertua. Ai Tali milik suku Mana terletak di Natar Utut, perkampungan di bawah Kampung Romanduru, di tanah milik Mo'an Ferdi. Ai tali milik suku Keytimu Wain terletak di belakang Lepo Gete suku Keytimu Wain yang sekarang ditinggali oleh Mo'an Rafael. Ai Tali milik suku Keytimu Lamen terletak di Natar Utut, di tanah milik Vendi Lagar. Ai Tali milik suku Klukut Mude Lau berada di kampung Ohe, di tanah milik Mo'an Manik. Ai tali milik suku Lio Watu Bao terletak di dekat mata air Romanduru, di tanah milik Mo'an Pitalis Noer. Ai tali milik suku Lio Lepo Gai berada di Natar Utut, di tanah milik Mo'an Gerpasius Padeng. Ai tali milik suku Wewe Niur berada di Kampung Eha, di tanah milik Mo'an Simon Nogor. Ai tali milik suku Wodon berada di Kampung
Woloklereng, di tanah milik Mo'an Henderikus Riko, pemimpin suku Wodon. Ai tali suku Ili Lewa berada di Kampung Eha, di tanah milik Mo'an Lajang.

Semua perkampungan tua di wilayah Krowe memiliki pola yang sama. Semuanya memiliki komponen wisung wangar, wu'a mahe, watu mahang, dan ai tali. Persamaan lainnya adalah kampung-kampung tua itu dikelilingi oleh siok linok ogor wokor. siok linok ogor wokor adalah tempat yang digunakan untuk buang air kecil dan buang air besar. Orang-orang pada jaman dulu, sebelum mempunyai kamar mandi sendiri-sendiri, melakukan aktivitas ekskresi di siok linok ogor wokorini. siok linok ogor wokorterdapat di bawah pohonpohon besar, biasanya berupa pohon beringin. Pohon-pohon ini tumbuh mengelilingi perkampungan sehingga dijadikan batas antara permukiman dan hutan atau tanah garapan. Karena pohon ini tumbuh mengelilingi perkampungan, orangorang menggunakan pohon terdekat dengan rumah masing-masing dan tidak saling bertukar dengan keluarga lain. Semak-semak yang tinggi digunakan sebagai penutup aktivitas ekskresi tersebut. Kotorankotoran berupa feses kemudian dimakan oleh binatang-binatang peliharaan, seperti babi yang hidup berkeliaran karena memang tidak dikandangkan. Setelah batas siok linok ogor wokor, terdapat hutan atau tanah garapan yang dimanfaatkan oleh warga untuk bercocok tanam atau mengumpulkan kayu. 


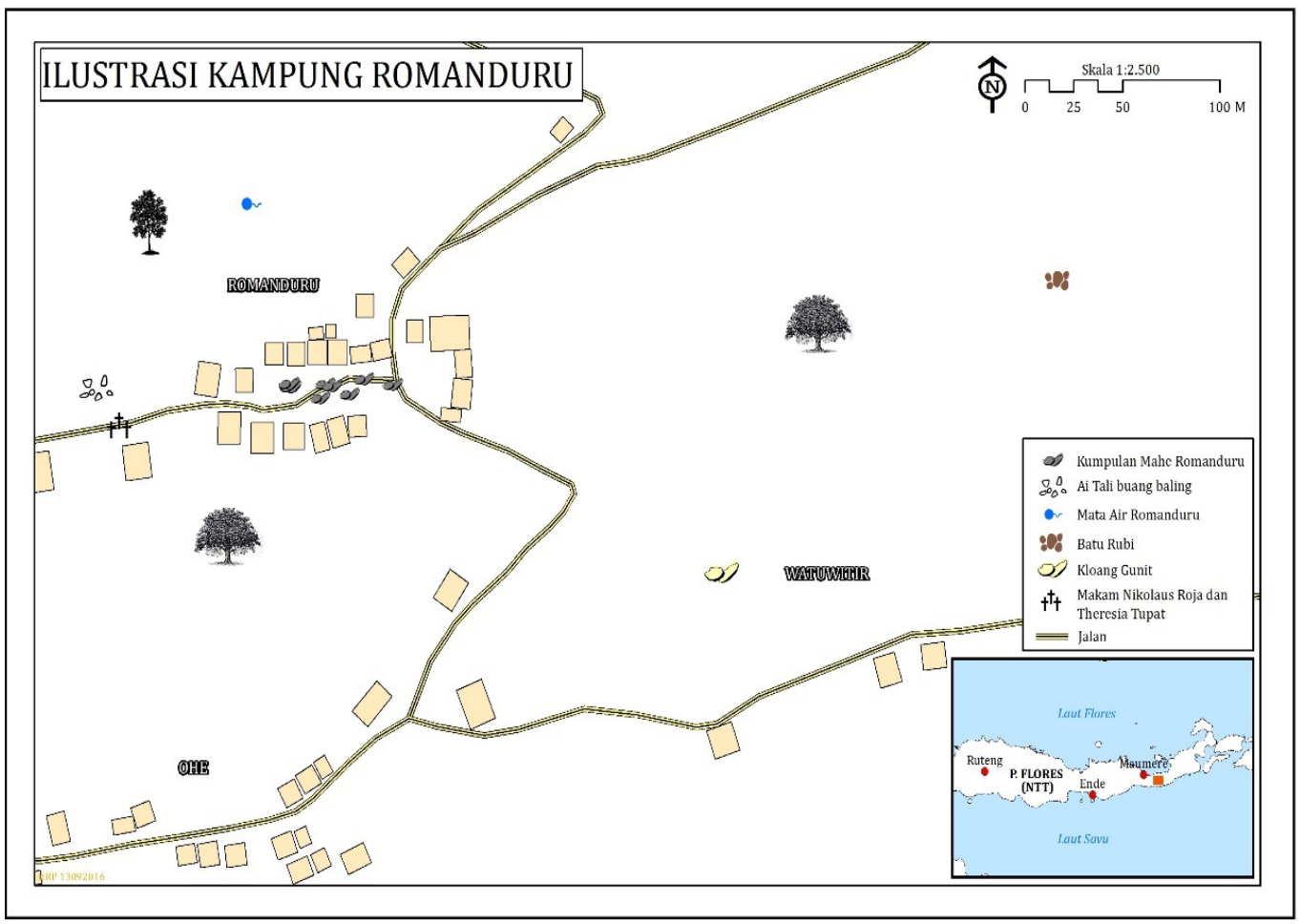

Gambar 4. Ilustrasi Perkampungan Romanduru (Sumber: penulis Ilustrasi oleh: Henki Riko Pratama, 2016)

DISKUSI DAN PEMBAHASAN

Wu'a Mahe sebagai simbol budaya materi bagi Ata Krowe dan relasinya dengan Mapitara

Keberadaan Wu'a Mahe ini penting bagi warga orang Krowe, termasuk warga Romanduru. Wu'a mahe adalah "rumah" bagi leluhur mereka. Peletakan wu'a mahe mengacu pada kepercayaan orang Krowe, yaitu menghadap ke arah Gunung Mapitara.

Cerita asal mula penghunian di tanah Flores menunjukkan arti penting Gunung Mapitara bagi orang Flores, terutama orang Krowe. Orang Krowe menganggap bahwa Mapitara merupakan tempat peristirahatan terakhir bagi arwah leluhur. Menurut Mo'an Yansen, "jadi, yang ada di Wu'a Mahe itu kan ada leluhur. Itu nanti mereka pergi ke Mapitara." Kesakralan Mapitara juga terlihat dalam syair-syair pada upacara adat, seperti misalnya pada upacara minta hujan, penyembuhan orang sakit, dan minta restu untuk pembangunan rumah. Salah satu contoh syair untuk pembangunan rumah:

"roa lorak reta mapidetun reta taragahar

murun piren"

Bati tali reta dahi detun

Syair tersebut menyebutkan tempat yang menghasilkan tali-tali untuk digunakan sebagai ikatan rumah. Roa lorak reta mapidetun adalah kayu-kayu keras yang digunakan untuk bahan bangunan. Mapidetun taragahar juga dikenal sebagai sebutan lain untuk Mapitara. 


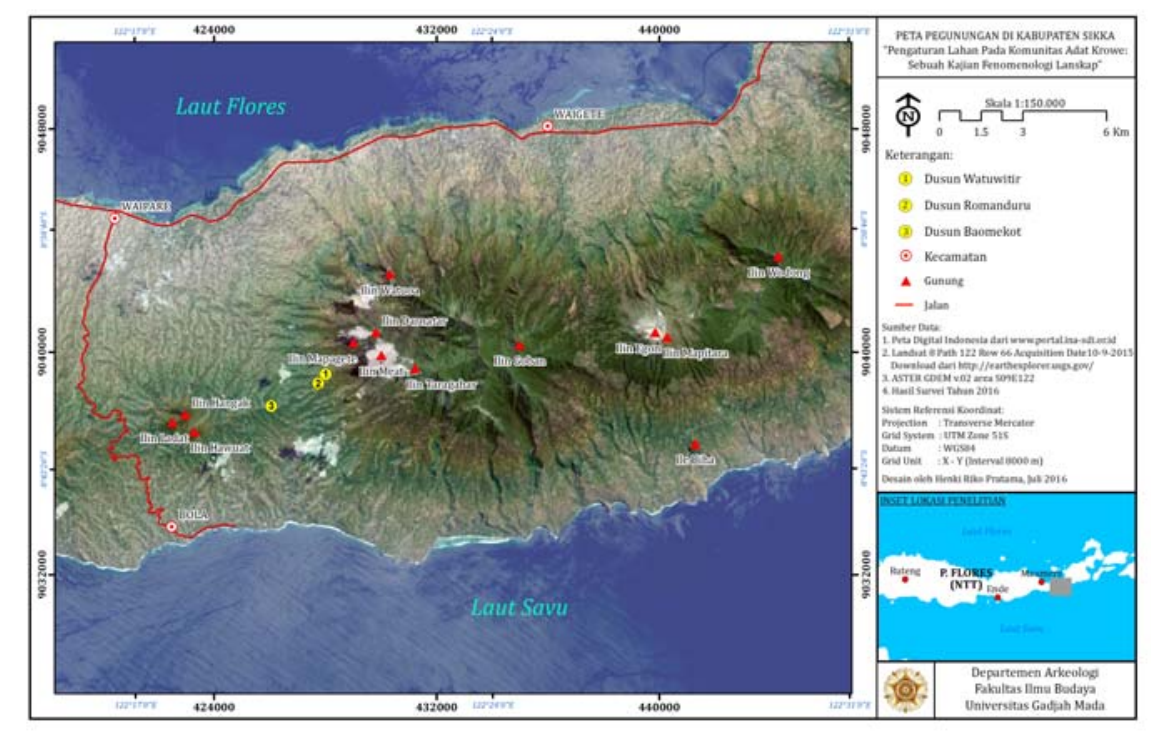

Gambar 5. Arah Gunung Mapitara dilihat dari Perkampungan Tua (sumber:Departemen Arkeologi, Fakultas Ilmu Budaya, Universitas Gadjah Mada)

\section{Wu'a Mahe dan Identitas Ata Krowe}

Dari uraian sebelumnya, dapat diketahui bahwa wu' a mahe merupakan simbol budaya materi yang paling pertama didirikan oleh suatu suku ketika mendiami tempat baru. Wu'a mahe dapat dikatakan sebagai identitas Ata Krowe untuk menandakan kehadiran mereka di sebuah tempat atau natar baru. Ata Krowe mengenal tradisi ngen atau berpindah tempat. Perpindahan ini biasanya didorong oleh kondisi lingkungan tempat asal yang tidak mendukung untuk keberlangsungan hidup mereka. Seperti yang telah disebutkan pula, perpindahan suku Buang Baling ke Romanduru dikarenakan mereka ingin mencari sumber air untuk memenuhi kebutuhan hidup mereka. Salah satu upaya untuk menelusuri tradisi ngen ini adalah dengan menelusuri keberadaan Wu'a mahe di kampungkampung tua. Setiap perkampungan tua pasti terdapat Wu'a Mahe yang merepresentasikan suku-suku di kampung tersebut.
Pendirian wu'a mahe di wilayah adat Krowe merupakan implementasi dari pengalaman nenek moyang yang diwariskan secara turun-temurun. Seperti yang telah disebutkan di uraian sebelumnya, di Kampung Romanduru gagasan pendirian wu'a mahe diinisiasi oleh suku Buang Baling selaku suku yang pertama kali datang ke kampung tersebut. Suku Buang Baling kemudian menyaratkan pendirian wu'a mahe kepada suku-suku yang datang belakangan dan menetap di Kampung Romanduru. Wu'a mahe kemudian mejadi simbol nenek moyang yang disepakati secara kolektif oleh Ata Krowe hingga saat ini. Begitu pula acuan kosmologis Ata Krowe yang mengarah ke Gunung Mapitara, konsep tersebut merupakan pengalaman yang didapatkan secara turun-temurun. Sudah menjadi kesepakatan kolektif bagi Ata Krowe untuk menjadikan Gunung Mapitara sebagai simbol kosmologis yang direpresentasikan melalui pendirian wu'a mahe. 
Wu'a mahe dapat disebut juga sebagai monumen. Wu'a mahe adalah monumen yang berelasi dengan dengan lanskap budaya Ata Krowe. Monumen ini sekaligus sebagai identitas bagi suku-suku yang mendiami suatu kampung tua. Monumen adalah simbol akan eksistensi Ata Krowe agar selalu terhubung dengan leluhurnya. Wu'a Mahe sebagai monumen juga berperan sebagai "focus"dari lanskap budaya perkampungan tua Ata Krowe. Tilley (1994: 204-205) mengatakan bahwa:

"Experience of the
ancestral past now came
into being within into
specifics setting of
monument and their
relationship to the outside
world.... The monument
both deployed and
capyured an ancestral
history. Acting an
mnemonic markers they
coded historicity and
sacred power in particular
places, creating a hierarchy
of valued points in the
landscape on pathways
channelling movement
through it and sustaining
knowledge of it .

Pernyataan Tilley tersebut tepat untuk diaplikasikan pada makna wu'a mahe bagi Ata Krowe. Wu'a mahe adalah media untuk mengingat sejarah dan asal-usul tiap suku yang pindah dari satu tempat ke tempat lain. Kemanapun mereka pergi, relasi mereka dengan Gunung Mapitara tidak akan pernah terputus. Hal tersebut ditunjukkan melalui arah hadap wu'a mahe yang sama di tiap-tiap perkampungan, semua menghadap ke arah Gunung Mapitara. Wu'a mahe sekaligus menjadi penghubung antara manusia dengan leluhurnya dan dianggap memiliki kesakralan. Wu'a mahe telah menjadi identitas bagi Ata Krowe yang menunjukkan siapa diri mereka tersebut. Wu'a mahe juga digunakan sebagai penanda struktur sosial antarsuku di tiap-tiap perkampungan dan sekaligus menjadi pusat dari lanskap budayanya.

\section{KESIMPULAN}

Ata Krowe dan Gunung Mapitara adalah bentuk relasi yang tidak dapat dipisahkan. Gunung Mapitara dipercaya sebagai tempat sakral karena merupakan tempat tinggal para leluhur. Gunung Mapitara dalam mitos lokal Ata Krowe, dipercaya sebagai tempat tinggal nenek moyang mereka yang datang dari tempat lain di luar Pulau Flores. Gunung Mapitara selanjutnya menjadi acuan bagi Ata Krowe dalam kehidupan mereka seharihari.

Media penghubung antara Ata Krowe dan Gunung Mapitara ini dikenal dengan sebutan wu'a mahe. Wu'a mahe adalah simbol budaya bendawi atau monumen bagi Ata Krowe. Wu'a mahe merupakan altar batu yang terdiri atas batu tegak dan batu mendatar berupa lempeng batu. Wu'a mahe menyimbolkan Ina Nian Tana Wawa, leluhur Ata Krowe yang disakralkan oleh orang-orang Krowe. Wu'a mahe selalu menghadap ke arah Gunung Mapitara, karena Gunung Mapitara diyakini merupakan tempat tinggal leluhur orang-orang Krowe. Ritualritual yang dilakukan di wu'a mahe inipun juga mengacu Gunung Mapitara sebagai arah hadapnya. 
Wu'a mahe juga dapat dikatakan sebagai monumen untuk selalu mengingat sejarah dan asalusul Ata Krowe di manapun mereka bermukim. Wu'a mahe juga bermakna sebagai identitas Ata Krowe, representasi suku-suku yang mendiami sebuah perkampungan atau yang dikenal sebagai natar. Jumlah wu'a mahe setiap kampung tua selalu sama dengan jumlah klan (suku) yang mendiami kampung tersebut. Seperti misalnya di Kampung Romanduru. Di kampung Romanduru terdapat 10 klan yang menghuni kampung tersebut. Kesepuluh klan, atau orang Krowe menyebutnya suku tersebut adalah suku Buang-Baling, Mana, Keytimu Wain, Keytimu Lamen, Klukut Kude Lau, Wodon, Lio Lepo Gai, Lio Watu Bao, Ili Lewa, dan Wewe Niur. Setiap suku yang mendiami sebuah kampung baru harus mendirikan wu'a mahe sebagai simbol mereka.

\section{UCAPAN TERIMA KASIH}

Penulis menyampaikan terima kasih kepada Dr. Mimi Savitri, M.A. dan Dra. Dwi Yani Yuniawati, M.Hum. yang telah memberikan bimbingan dalam penulisan artikel ini. Ucapan terima kasih juga penulis sampaikan kepada Unit Penelitian FIB UGM yang telah memberikan kesempatan kepada penulis untuk melakukan penelitian di Kabupaten Sikka. Tidak lupa penulis juga menyampaikan terima kasih kepada seluruh informan di wilayah adat Krowe, terutama kepada Bapak Don, Bapak Yansen, Bapak Victor, Bapak Goris, dan pihak-pihak lain yang tidak dapat penulis sebutkan satu per satu. 


\section{DAFTAR PUSTAKA}

Ahimsa-Putra, Heddy Shri. 2012. "Fenomenologi Agama: Pendekatan Fenomenologi untuk Memahami Agama" dalam Jurnal Walisongo, Volume 20, Nomor 2, November 2012. Halaman 271-304.

Butterworth, David J. 2008 Lessons of th Ancestors Ritual, Education and the Ecology of Mind in an Indonesian Community. University of Melbourne (Not Published Manuscript).

2009 Precedence, Contestation, and the Deployment of Sacred Authority in a Florenese Village. At Vischer, Michael P. Precedence: "Social Diferentiation in the Austronesian Worldhalaman 167-190”. Canbera: ANU E Press.

2011 Ritual Preparation for Living dapat diakses melalui http://dx.doi.org/10.1080/13639811.2011.547729

Hefner, Robert W. 1989. Hindu Javaneese, Tengger Tradition and Islam. UK: Princenton University Press.

Kartakusuma, Richardiana Kadarisman. 2006. "Rasionalisasi Ideologi Sunda Wiwitan (Kabuyutan): Penyatuan Diri Urang Sunda Kepada Gunung sebagai Lambang Semesta (Kosmis)" dalam Berkala Arkeologi Tahun XXVI Edisi No. 1/2006. Yogyakarta: Balai Arkeologi Yogyakarta. Halaman 86-125.

Kusen, dkk. 1993. Agama dan Kepercayaan Masyarakat Majaphit dalam 700 tahun Majapahit (1293-1993) Suatu Bunga Rampai. Surabaya: Dinas Pariwisata Daerah Propinsi Daerah Tingkat I Jawa Timur.

Metzner,Joachim K. 1982. Agriculture and population pressure in Sikka, Isle of Flores: A contribution to the study of the stability of agricultural systems in the wet and dry tropics. Canberra: Australian National University.

Matutina, Fransiskan Purnamawati. 1995. Peninggalan-peninggalan Megalitik di Kampung Dobo, Desa Ian Tena, Kecamatan Kewapante, Kabupaten Sikka, Nusa Tenggara Timur. Skripsi. Denpasar: Jurusan Arkeologi Fakultas Sastra Universitas Udayana.

Santosa, Langgeng Wahyu dan Lutfi Muta'ali. 2014. Bentang Alam dan Bentang Budaya, Panduan Kuliah Kerja Lapangan Pengenalan Bentang Lahan. Yogyakarta: Badan Penerbit Fakultas Geografi Universitas Gadjah Mada.

Sero, Theresia. 2015. Watu Mahe Dalam Struktur Masyarakat Romanduru, Desa Rubit, Kecamatan Hewokloang, Kabupaten Sikka. Skripsi. Ende: Program 
Studi Pendidikan Sejarah Fakultas Keguruan dan IImu Pendidikan Universitas Flores.

Shanks, Michael dan Christopher Tilley. 1982. "Ideology, Symbolic Power and Ritual Communication: a Reinterpretation of Neolithic mortuary practices". In New Directions in Archaeology, Symbolic and Structural Archaeology, Edited by Ian Hodder. UK: Cambridge University Press. Halaman 129154.

Sudarmadi, Tular. 1999. An Ethnoarchaeological Study Of The Ngada, A megalithic culture in Central Flores, Indonesia. A thesis in Univesity of New England, Armidale, N.S.W.

Suyono, R.P. Capt. 2009. Mistisisme Tengger. Yogyakarta: LkiS.

Tilley, Christopher. 1994. A Phenomenology of Landscape. UK: Berg Publishers.

Tule, Philipus. 2006. "We Are Children of The Land: A Keo Perspective" in. Sharing The Earth, Dividing The Land: Land and terotory in the Austronesian world. Edited by Reuter, Thomas. Canbera: ANU E Press. Halaman 211-236.

Utama, Bakti. 2014 Sketsa Transformasi Upacara Adat Pada Komunitas Adat Komunitas Adat Krowe di Kabupaten Sikka. Jakarta: Kementerian Pendidikan dan Kebudayaan.

Wales, Quaritch H.G. The Sacred Mountain in the Old Asiatic Religion. Paper at the Ivth International Congress of Anthropological and Ethnological Science at Vienna, on $6^{\text {th }}$ September, 1952. 